\title{
O fermento de Gramsci na América Latina e no Serviço Social
}

\author{
Ana Lole ${ }^{1}$ \\ Ivete Simionatto ${ }^{2}$ \\ Marina Maciel Abreu ${ }^{3}$
}

Criar uma nova cultura não significa apenas fazer individualmente descobertas 'originais'; significa também, e sobretudo, difundir criticamente verdades já descobertas, 'socializá-las', por assim dizer; e, portanto, transformá-las em base de ações vitais, em elemento de coordenação e de ordem intelectual e moral. (GRAMSCI, CC, 1999, p. 96; Q, 1977, p.1378).

Em 2021, quando comemoramos 130 anos do nascimento de Antonio Gramsci (1891-1937), é inquestionável a presença de suas ideias como fermento às lutas que necessitam ser travadas para superar este "mundo grande, terrivel e complicado", expressão com a qual ele traduziu o seu tempo e, triste e profeticamente, também o tempo presente. Um dos maiores marxistas do século XX, a difusão e a tradução de suas obras em inúmeros países e continentes asseveram a vitalidade de seu pensamento na interpretação e transformação da realidade diante das atuais condições sócio-históricas crivadas de exploração, desigualdade e injustiças. Especialmente na América Latina onde vivenciamos as amarras da colonialidade e do capitalismo periférico, o rico e fecundo legado de Gramsci evidencia o seu potencial para a apreensão das particularidades latino-americanas, com destaque para a brasileira.

Em suas reflexões e estudos Gramsci buscou evidenciar a importância de um agir político ativo como oportunidade para possibilitar que as classes subalternas, a partir da realidade em que vivem e de 
suas observações transformadas em saber, avancem na consciência das condições de exploração e subalternidade que estruturam a sociedade capitalista e o quanto é possível construir outras formas de viver. No caderno 13, §2, Gramsci expõe a relevância de se avaliar a realidade nos diversos aspectos em que ela se manifesta, em suas múltiplas determinações, incluindo as estratégias e táticas que podem ser utilizadas politicamente, as relações de forças presentes em cada conjuntura e os termos de disputa da hegemonia.

Para Cramsci é necessário desenvolver uma "autoconsciência crítica", isto é, que seja histórica e política, que possa contar com organizadores e dirigentes comprometidos com a construção da vontade coletiva e a superação das relações entre governantes e governados, dirigentes e dirigidos. E, para tal, menciona no caderno 11, §12, que para um grupo se destacar e tornar-se independente "para si" é imprescindivel a disciplina e a organização, mas igualmente a aquisição de uma base conceitual e filosófica expressas pela filosofia da práxis, na unidade entre teoria e prática, pensamento e ação. Acrescenta que é preciso considerar o conhecimento como arma e transformá-lo em provisões para possibilitar a transformação da realidade concreta.

Cramsci considera que ao filósofo da práxis cabe traduzir o que vem das massas, criando estratégias para o alcance de realizações. Diz-nos que não é possível a existência de uma teoria geral que se adéque a todas as realidades, porque ela sempre será falsa e não há uma verdade que seja eterna. Na filosofia da práxis é fundamental a busca pela verdade, que deverá ser transformada em ideologia, como resultado de um pensamento organizado por um grupo que deseja atuar. Seu valor será determinado pelo grau de conexão que tem com a realidade, porém não devemos perder de vista que a produção da verdade tem caráter transitório. E, nesse sentido, Gramsci abre uma direção completamente nova.

Vivem-se regressões civilizatórias sem precedentes na história da humanidade, no âmbito da atual crise econômica, política, cultural do 
sistema capitalista mundializado, agravado, em 2020, em sua dimensão sanitária com a devastação de vidas humanas causada pela pandemia da Covid-194. Acirra-se a crise cultural, a crise de sociabilidade, de sentido da existência, como diria Bihr (1998), em que avança o conservadorismo reacionário em todas as dimensões da vida. Torna-se imprescindivel e necessário fortalecer o debate do marxismo, na sustentação da luta social nos diferentes espaços, com destaque nas mediações acadêmicas, no embate permanente às forças do retrocesso, adensado desde a chamada crise de paradigmas, em que penetra e se espalha o pensamento pós-moderno, embora nem sempre alinhado ao conservadorismo, porém favorece a sua disseminação. Avançar nesse debate, é um grande desafio a enfrentar, na medida em que o marxismo, na batalha das ideias tem sido o principal alvo da ofensiva conservadora reacionária, na velha guerra ao comunismo, junto à qual ganham força ideias e práticas neofascistas que alimentam e são alimentadas pelos fundamentalismos: econômico e religioso. Nesse confronto, a ofensiva contra o pensamento de Gramsci ganha destaque, tido pelos defensores do sistema dominante como a referência ideológica de maior penetração na América Latina.

Neste contexto de crise e de barbárie cultural, em que "o velho morre e o novo não pode nascer", este desafio impõe: a organização dos grupos subalternos enquanto classe, força hegemônica, na resistência, no enfrentamento e na superação do "velho", que é o capitalismo; e o fortalecimento da construção de uma nova "vontade coletiva nacional-popular" com base na filosofia da práxis, a partir da qual essa luta é uma luta perpétua, como diria Gramsci (1999, [CC 10]).

\section{Recepção de Gramsci no Brasil e no Serviço Social}

A difusão do pensamento de Gramsci na América Latina percorreu caminhos singulares. Suas primeiras ideias anunciadas pelo revolucionário peruano José Carlos Mariátegui, ainda nos anos 1920, encontrarão terreno fértil a partir do final dos anos 1950 com a publicação 
das Cartas e dos Cadernos do cárcere na Argentina o mesmo ocorrendo no Brasil na metade dos anos 1960, expraiando-se nos anos posteriores mesmo sob as complexas e desafiadoras condições impostas pelos regimes ditatoriais. Pode-se dizer que a partir dos anos 1980 a obra de Gramsci passa efetivamente a ser conhecida e difundida em diversos países avançando de maneira constante e expressiva entre intelectuais, cientistas sociais e políticos no continente latino-americano. Na geografia latino-americana Hector P. Agosti, José Aricó, Juan Carlos Portantiero, René Zavaleta Mercado, Carlos Nelson Coutinho, Dora Kanoussi e tantos outros contribuíram decisivamente para a difusão do pensamento gramsciano e para a incorporação de seu léxico na leitura e transformação da realidade. Categorias como Estado, sociedade civil, hegemonia, revolução passiva, nacional-popular tornaram-se parte da cultura política latino-americana e foram fundamentais para a compreensão da formação sócio-histórica de cada país, das condições de subalternidade e dependência, a configuração das classes sociais, mas igualmente, das lutas sociais de resistência no enfrentamento às ditaduras militares. Considerado como “o maior teórico marxista da política” (COUTINHO, 2008), a "recepção do pensamento de Gramsci na América Latina foi sempre caracterizada por uma leitura em chave política, e assim se desenvolveu", conforme aponta Burgos no artigo que compõe este dossiê.

No Brasil, as primeiras obras do marxista italiano, traduzidas e publicadas, também remontam o início dos anos 1960, sendo interrompidas pela instauração do regime militar e retomadas somente na metade dos anos 1970 com o retorno às liberdades democráticas e com a chamada "abertura política”. Verifica-se a partir de então, um verdadeiro boom gramsciano, dando início à uma nova fase da recepção das ideias de Gramsci no Brasil, quando passam a ser amplamente assimiladas nos meios político e acadêmico pelas mais diversas áreas do conhecimento, especialmente das Ciências Humanas e Sociais. Após um longo período e de inúmeras reedições da edição togliattiana, no 
final dos anos 1990, os estudos gramscianos são adensados com a nova edição dos Cadernos e Cartas do cárcere e dos Escritos políticos, organizada por Carlos Nelson Coutinho, Marco Aurelio Nogueira e Luiz Sérgio Henriques, bem como, do Dicionário Gramsciano organizado pelos marxistas italianos Guido Liguori e Pasquale Voza (2017).

A aproximação do Serviço Social ao pensamento gramsciano também tem como marco o final dos anos 1970 no contexto da conjuntura aberta pela crise da ditadura militar, da dinâmica mesma da realidade, das pulsões políticas provocadas pela reinserção dos movimentos sociais e populares na cena política, fenômenos que alavancaram a busca do rompimento com o tradicionalismo profissional e as bases conservadoras da profissão. Agrega-se a essa conjuntura a retomada das sementes lançadas pelo Movimento de Reconceituação, cuja particularidade no Brasil ancorou-se pelo Método Belo Horizonte (BH) e o III Congresso Brasileiro de Assistentes Sociais realizado em 1979, referências históricas no processo de "intenção de ruptura" (NETTO, 1991) mediante o questionamento das bases teóricas, políticas e ideológicas do Serviço Social através dos suportes buscados no pensamento marxista.

Entre final dos anos 1970 e início dos anos 1980, o processo de ruptura com o tradicionalismo profissional ganha novos impulsos com a obra de Marilda lamamoto e Raul de Carvalho (1982), demarcando a inserção do pensamento marxiano no Serviço Social, contribuição inédita para compreender a profissão a partir de uma interpretação teórico-metodológica fundada na matriz crítico-dialética. Ao lado destes marcos propulsores também situa-se a aproximação do Serviço Social ao pensamento gramsciano, especialmente através do protagonismo do curso de Mestrado em Serviço Social da PUC-Rio. O grupo formado pelo programa sob a orientação da professora Miriam Limoeiro Cardoso, produziu trabalhos marcantes no desenvolvimento teórico do Serviço Social no eixo da tradição marxista, destacando-se o protagonismo nos embates travados com a 
vertente fenomenológica e a contribuição decisiva na ampliação das bases teóricas da profissão no espectro do marxismo.

O pensamento gramsciano apresentou-se como uma alternativa tanto à perspectiva economicista presente na literatura marxista dos anos 1970, quanto à fenomenologia, que buscava reatualizar os pressupostos do conservadorismo na reorientação teórica e prática do Serviço Social. No delineamento de novas propostas alinhadas ao eixo da tradição marxista, o aporte teórico do comunista italiano contribuiu sobremaneira para operar mudanças significativas tanto no referencial teórico-metodológico quanto nas mediações com o fazer prático-operativo e o compromisso com os interesses das classes subalternas (SIMIONATTO, 2018). Categorias como Estado, sociedade civil, sociedade política, hegemonia, intelectuais, filosofia da práxis, classes subalternas, entre outras, permitiram ao Serviço Social interrogar-se sobre questões relativas às instâncias estrutural e superestrutural, com problematizações relativas não somente à esfera econômica, mas também política, ideológica e cultural (YAZBEK, 2009; SIMIONATTO, 2021). A relação dialética entre estrutura e superestrutura, fio condutor do pensamento gramsciano para ler a realidade e orientar a intervenção para transformá-la, sem jamais separar economia e política, cultura e necessidades sociais, foi um ponto decisivo para o questionamento das posições reducionistas do economicismo e do marxismo vulgar, originários especialmente da Segunda Internacional, que vicejavam no debate acadêmico e político da época.

A presença de Gramsci no Serviço Social se amplia na década de 1980, com conquistas importantes na discussão teórico-metodológica, com a implantação do currículo de 1982, com a direção social da formação e da prática profıssionais, afırmadas na disputa da hegemonia com o conservadorismo e o pragmatismo, mas também por meio da atuação e organização política da categoria. A inovadora contribuição de Gramsci ao marxismo, através da filosofia da práxis, impulsionou o aprofundamento dos estudos sobre o método crítico dialético, a 
imprescindivel unidade entre teoria e prática, entre indivíduo e sociedade, entre pensamento e ação (ABREU; CARDOSO, 1989).

Os eventos ocorridos na conjuntura mundial após 1989 com a queda do socialismo real, afetaram não somente a Europa, mas igualmente toda a América Latina. Fortalecidos pelo projeto neoliberal, pelos ventos da onda pós-moderna, pela proclamação do "fım das ideologias", pelo arrefecimento dos sujeitos políticos coletivos, esses fatos marcantes na escalada de descrédito no marxismo e na desqualificação da proposta comunista provocaram, consequentemente, um refluxo no interesse relativo às ideias gramscianas. Mesmo assim, o Serviço Social prosseguiu os debates nos círculos acadêmicos a partir da mediação de suas instâncias organizativas, na preocupação com a formação profissional e a organização da categoria, desencadeando neste período, o processo de revisão curricular que culmina com as Diretrizes Curriculares assentadas nas premissas teórico-metodológicas buscadas especialmente em Marx e no eixo da tradição marxista com destaque para Gramsci e Lukács.

Dos anos 1990 aos dias atuais, é possível constatar uma notável ampliação do interesse do Serviço Social pelo pensamento de Gramsci expressa em suas produções teóricas publicadas em livros, capítulos de livros, artigos científicos, trabalhos acadêmicos (teses de doutorado e dissertações de mestrado), trabalhos apresentados em congressos nacionais e internacionais. Os conceitos gramscianos são tomados tanto para compreender o movimento geral da sociedade, os projetos societários em disputa, as expressões do Estado e da sociedade civil, o papel e a função dos intelectuais na construção da hegemonia, como chaves analíticas ao desvendamento das diversas expressões da "questão social", suas refrações na particularidade da profissão, na construção de pautas interventivas na direção dos interesses imediatos e mediatos dos sujeitos atingidos por elas - amplos segmentos das classes e grupos subalternos. O fortalecimento e a consolidação da pós-graduação e a defesa do projeto ético-político profissional impul- 
sionaram fecundos estudos sobre o pensamento gramsciano e a tradição marxista em um momento de influxo do marxismo nos debates acadêmico e político (SIMIONATTO, 2018). Destaca-se o aprofundamento dos estudos, tanto do ponto de vista da ação política quanto de investigações filológicas, necessárias para compreender e percorrer o “laboratório gramsciano", como também a expansão dos grupos de pesquisa e a realização de seminários regionais e nacionais, contribuições de grande relevância na socialização e difusão do pensamento de Gramsci, na formação de uma cultura política crítica no âmbito do Serviço Social e de interlocução com outras áreas do conhecimento, conforme revelam os artigos deste dossiê.

Se os conceitos gramscianos foram essenciais no enfrentamento ao conservadorismo que historicamente marcou a profissão, para compreender e desvendar as relações de força em cada conjuntura e perspectivar mudanças na totalidade da vida social, seguem de extrema relevância na compreensão da atual crise orgânica que vivemos que atravessa as esferas econômica, social, moral e política, no combate às posturas antimarxistas, anti-intelectuais e neoconservadoras que grassam nos meios acadêmico e profissional e que tendem ao retrocesso das conquistas do projeto ético-político profissional e de seus princípios emancipatórios.

Destacamos a relevância do pensamento de Gramsci e de suas categorias que permanecem projetando luzes para interpretar as intensas mudanças destes tempos em que os princípios e pressupostos da hegemonia neoliberal seguem realizando a sua "reforma intelectual e moral" a serviço dos dominantes. Podemos dizer, desta forma, que a leitura de Cramsci é impreterível na atualidade, para seguir nos iluminando na compreensão das desafiadoras questões postas do cenário mundial e, particularmente, de Nuestra América. O seu legado e o seu discurso iluminam este tempo histórico, fortalecendo as lutas voltadas à construção de uma nova ordem societária, sem dominação/exploração de classe, raça/etnia e gênero, nos 
colocando, portanto, a atualidade da perspectiva da revolução que envolve a luta pela democracia e pelo socialismo.

\section{Apresentação do dossiê}

Neste ano de comemoração dos 130 anos do nascimento de Gramsci, a Revista O Social em Questão para comemorar o nascimento do filósofo italiano traz neste número o dossiê temático O fermento de Gramsci na América Latina e no Serviço Social, o qual buscou evidenciar a potencialidade dos escritos gramscianos para a interpretação da América Latina, em especial, para o Brasil e o Serviço Social.

Tendo como ponto central a tradutibilidade de Gramsci para os trópicos e para o Serviço Social, o presente dossiê recebeu contribuições que abordam a atualidade do pensamento gramsciano para os estudos sobre as lutas e os processos revolucionários na América Latina, em particular no Brasil; as análises teóricas de Cramsci sobre o fascismo, filosofia da práxis e hegemonia; e a influência de Gramsci para a ruptura do Serviço Social com o conservadorismo.

O artigo que abre o dossiê é de Raúl Burgos intitulado Uma escola latino-americana de hegemonia? Elementos para uma proposta interpretativa. Burgos traz uma descrição das principais correntes de recepção do conceito gramsciano de hegemonia na América Latina. O autor realizada uma exposição geográfica e temática, com o objetivo de evidenciar os contornos mais relevantes da "escola latino-americana da hegemonia", como chamou em seu artigo.

Claudio Reis em A periferia da periferia e o pensamento de Antonio Gramsci aborda sobre a tradução, a recepção e a difusão de Gramsci no Brasil, considerado um país de periferia do capital. Essa experiência, segundo o autor, pode ser traduzida para os demais países da América Latina. O autor traz a experiência do Grupo de Estudos Antonio Gramsci (CEA) da Universidade Federal da Grande Dourados (UFCD) para mostrar a importância da produção do conhecimento e, ao mesmo tempo, mostrar a tradução das categorias gramscianas para a leitura do agronegócio brasileiro. 
demias de Giovanni Semeraro traz elementos para refletirmos sobre o contexto atual. O autor mostra que a realidade posta pela pandemia da Covid-19 não é um acidente de percurso e sim resultado de um sistema "que chegou aos limites mais absurdos de destruição e de letalidade". Semeraro expõe o cenário catastrófico que se abateu no Brasil, mas, também, aponta, com lentes gramscianas, “caminhos não só para resistir, mas, principalmente para enfrentar a barbárie e lançar as bases para um novo projeto de sociedade".

O texto de Débora Ruviaro e Mirele Hashimoto Siqueira, O debate gramsciano sobre o fascismo: um fascismo “à brasileira"?, apresenta o debate sobre fascismo a partir da ótica gramsciana, discutindo a apropriação deste conceito para a compreensão da conjuntura atual brasileira. Para isso, as autoras recuperam o conceito de fascismo no tempo e na realidade de Cramsci para realizar a tradução para a realidade periférica, na qual o Brasil se encontra. As autoras apresentam em seu texto os elementos da vida de Gramsci, de sua práxis política e de seu encarceramento no regime fascista de Mussolini. Analisam o fenômeno do fascismo por Gramsci a partir de seus escritos pré-carcerários e mostram o exercício do filósofo sardo no cárcere de pensá-lo como uma forma de revolução passiva. E ao discorrerem sobre o contexto de fascismo "à brasileira" recuperam a onda de protestos de 2013 até a pandemia da Covid-19 mostrando como as categorias de Cramsci contribuem para a leitura da conjuntura brasileira atual.

Na mesma direção, o texto de Douglas Ribeiro Barboza intitulado Natureza de classe e características particulares do fascismo: contribuições de Cramsci para pensarmos o Brasil atual resgata as principais análises de Gramsci sobre a forma através da qual o fascismo se impôs como alternativa para a sociedade italiana, desde uma perspectiva da luta econômica, política e ideológica travada pelas classes sociais e as suas frações. A compreensão gramsciana acerca da consolidação do fascismo como uma forma de Estado e uma forma 
de regime específico se constitui como um eixo central fundamental através do qual o autor busca desvelar, com as devidas mediações presentes o atual processo de fascistização da sociedade brasileira impulsionado com a ascensão de Bolsonaro ao poder.

O artigo de Sérgio Miguel Turcatto, Gramsci e os apontamentos da "nova filosofia", trata dos fundamentos da filosofia marxista no pensamento de Cramsci nos Cadernos miscelâneos, desenvolvida nos Apontamentos Filosóficos dos Cadernos 4, 7 e 8, entre outubro de 1930 e nos primeiros meses de 1932. Trata-se de uma rigorosa pesquisa teórica de grande relevância na produção de conhecimentos sobre o pensamento de Gramsci, com destaque para a filosofia da práxis.

Em Música popular, emoção e política: a batalha dos afetos, Eduardo Granja Coutinho aborda temática relevante no âmbito do debate sobre ideologia e cultura na luta de hegemonias, com importante contribuição para a análise do momento presente marcado por forte crise política no contexto da crise econômica e disputa ideológica, determinadas pela crise contemporânea mundial do sistema capitalista ao mesmo tempo agravantes no acirramento da luta de classes. O artigo traz o tema da cultura com foco na música popular como fonte da paixão e elemento contraditório de dominação e libertação. A análise de Coutinho centra-se na canção de protesto latino-americana dos anos 1960 e 1970.

O artigo Filosofia da práxis, pós-colonialismos e Serviço Social no estudo da América Latina, de Joelcio Jackson Lima Silva, Telma Cristiane Sasso de Lima, Elídio Alexandre Borges Marques, aborda temática altamente relevante para o debate na área das ciências sociais e humanas, e particularmente no Serviço Social pela discussão sobre questões relacionadas ao conteúdo ético-político que alicerça o novo projeto profissional crítico hegemônico desde a movimento da "virada" em 1979, conteúdo ainda pouco explorado. É substantiva a discussão de fontes que exploram correntes de pensamentos pós-colonial latino-americana, e da influência marxista mediante uma aproximação entre "estudos decoloniais" e aportes do pensamen- 
to gramsciano sobre a filosofia da práxis, que os autores demarcam como "filosofia da práxis gramsciana".

O artigo de Luis Alberto Vivero Arriagada intitulado El trabajador social como intelectual orgánico. Análisis a partir de la crisis histórico-política de Chile traz uma análise do cenário que foi gerado no Chile, a partir da explosão social popular, a partir das contribuições de Gramsci, em especial do conceito de intelectual orgânico. Segundo o autor, o cenário de crise social e política permitiria criar as condições para uma reforma cultural e moral. Nesta dinâmica de lutas pela hegemonia, o Serviço Social experimentou rupturas com os atrasos conservadores deixados pelo legado da ditadura e o longo período pós autoritário de transição democrática.

Em O pensamento de Gramsci e o Estado brasileiro: contribuições ao Serviço Social, Salyanna de Souza Silva aborda uma análise sobre a formação do Estado brasileiro a partir das contribuições teóricas de Gramsci. Trata-se de um estudo de revisão de literatura de categorias gramscianas, atuais e importantes para a compreensão da realidade nacional, e cotejadas com as reflexões de autores como Carlos Nelson Coutinho (1993) e Florestan Fernandes (2006). O tema é atual e de grande relevância para pensar a realidade contemporânea e as mediações com o Serviço Social.

O dossiê também traz duas resenhas. A primeira escrita por Maria Julia de Paiva da obra de Eduardo Granja Coutinho intitulada A paixão segundo Antonio Gramsci, publicada em 2020 pela editora Mórula. E a segunda escrita por Pedro Cláudio Cunca Bocayuva da obra Antonio Gramsci, o homem filósofo, de Gianni Fresu, publicada pela Boitempo em 2020.

O dossiê buscou demonstrar, destacadamente, a influência do pensador sardo para uma leitura da América latina, particularmente do Brasil e do Serviço Social

Desejamos uma boa leitura! 


\section{Referências}

ABREU, Marina Maciel; CARDOSO, Franci, Comes. Metodologia do Serviço Social: a práxis como base conceitual. Cadernos ABESS, São Paulo, n. 3, 1989.

BIHR, Alain. Da grande noite à alternativa: o movimento operário europeu em crise. São Paulo: Boitempo, 1998.

COUTINHO, Carlos Nelson. A presença de Gramsci no Brasil. Em Pauta, Rio de Janeiro, n. 22, p. 37-44, 2008.

GRAMSCI, Antonio. Cadernos do cárcere. Edição e tradução de Carlos Nelson Coutinho; Co-edição de Luiz Sérgio Henriques e Marco Aurélio Nogueira. Rio de Janeiro: Civilização Brasileira, 1999. (6 volumes)

GRAMSCI, Antonio. Quaderni del carcere, a cura di V. Gerratana. 4 voll. Torino: Einaudi, 1977.

IAMAMOTO, Marilda V.; CARVALHO, Raul de. Relações sociais e serviço social no Brasil: esboço de uma interpretação histórico-metodológica. São Paulo: Cortez, 1982.

LICUORI, Guido; VOZA, Pasquale (Org.). Dicionário gramsciano (1926-1937). 1 ed. São Paulo: Boitempo, 2017.

NETTO, José Paulo. Ditadura e serviço social: uma análise do serviço social no Brasil pós-64. São Paulo: Cortez, 1991.

SIMIONATTO, Ivete. "Gramsci de um século ao outro": sua presença no Serviço Social brasileiro. Revista Libertas, Juiz de Fora, v. 21, n. 1, p. 1-19, jan./jun. 2021.

SIMIONATTO, Ivete. As abordagens marxistas no estudo dos fundamentos do Serviço Social. In: GUERRA, Yolanda et al. (Org.). Serviço Social e seus fundamentos: conhecimento e crítica. Campinas: Papel Social, 2018.

YAZBEK, Maria Carmelita. O significado sócio-histórico da profissão. In: CFESS; ABEPPS (Org.). Serviço Social: Direitos sociais e competências profissionais. Brasília: CFESS/ABEPSS/CEAD e UnB, 2009.

\section{Notas}

1 Assistente Social. Doutora em Serviço Social pela Pontifícia Universidade Católica do Rio de Janeiro (PUC-Rio). Professora do Departamento de Serviço Social da PUC-Rio. Brasil. ORCID-iD: https://orcid.org/0000-0003-2991-3594. E-mail: analole@gmail.com 
2 Assistente Social. Doutora em Serviço Social pela Pontifícia Universidade Católica de São Paulo (PUC-SP). Professora do Programa de Pós-graduação em Serviço Social da Universidade Federal de Santa Catarina (UFSC). Brasil. ORCID-iD: https://orcid.org/0000-0002-0564-6658 E-mail: ivetesimionatto57@gmail.com

3 Assistente Social. Doutora em Serviço Social pela Pontifícia Universidade Católica de São Paulo (PUC-SP). Professora aposentada da Universidade Federal do Maranhão (UFMA), vinculada ao programa de pós-Graduação em Políticas Públicas (UFMA). Brasil. ORCID-iD: https://orcid.org/0000-0002-4355-9870 E-mail: maciel.m@uol.com.br

4 A pandemia de Covid-19, doença causada pelo novo coronavírus (Sars-Cov-2), foi decretada pela Organização Mundial da Saúde (OMS) no dia 11 de março de 2020. A mudança de classificação não se deu pela gravidade da doença, e sim pela disseminação geográfica rápida que a Covid-19 apresentou. A mudança na classificação pela OMS foi para obrigar os países a tomarem medidas preventivas à contaminação. 